\title{
DOCÊNCIA JURÍDICA
}

Danielle Yurie Moura da Silva, Cristiano Amaral G. Di Giorgi

Universidade do Oeste Paulista - UNOESTE, Mestrado em Educação, Presidente Prudente - SP. E-mail: danyurie25@gmail.com

\section{RESUMO}

O presente artigo baseia-se na abordagem da atuação do docente de direito. Sabendo que a formação dos discentes está cada vez mais tecnicista e menos humanista. E que existem fatores que contribuem para isso, como a grande quantidade de cursos ofertados, a aprovação no Exame Unificado da OAB e a nota do ENADE que a Instituição de Ensino Superior possui. Entretanto, a maior dificuldade encontrada é a falta de preparo pedagógico dos docentes. No magistério jurídico é comum que profissionais de carreiras jurídicas lecionem nas disciplinas do curso. Porém o que se percebe é que muitos utilizam o positivismo como método didático de transmissão de conteúdo. Assim, sabe-se que o saber fazer não equivale ao saber ensinar. O método aplicado foi o hipotético-dedutivo, com pesquisas de cunho teórico e bibliográfico. Diante disso novos paradigmas são expostos ao docente para que este ajude na formação de profissionais mais reflexivos.

Palavras-chaves: Docência Jurídica - Práticas Pedagógicas - Profissional Reflexivo

\section{LEGAL TEACHING}

\section{ABSTRACT}

This article is based on the approach of the teaching of law. Knowing that the formation of the students is increasingly more technical and less humanistic. And that there are factors that contribute to this, such as the large number of courses offered, the approval in the Unified Examination of the $O A B$ and the note of the ENADE that the Institution of Higher Education possesses. However, the greatest difficulty is the lack of pedagogical preparation of teachers. In legal teaching it is common for legal career professionals to teach in the course subjects. But what is perceived is that many use positivism as a didactic method of content transmission. Thus, knowing that doing is not equivalent to knowing how to teach. The method applied was hypothetico-deductive, with theoretical and bibliographic research. Faced with this new paradigms are exposed to the teacher so that this helps in the formation of more reflective professionals.

Keywords: Legal Teaching - Pedagogical Practices - Reflective Professional 


\section{INTRODUÇÃO}

A docência por profissionais de carreiras jurídicas no curso de Direito é algo comum. Contudo diante da crise que o sistema educacional, e neste caso, o jurídico, vivencia quanto a sua qualidade, mostra a necessidade dos docentes conhecerem mais as questões pedagógicas no ensino superior, para que se busque além de uma qualificação acadêmica, formar profissionais mais humanistas.

Diferentemente da docência nos níveis básicos da educação, a acadêmica sempre teve como crença que os profissionais que sabiam fazer também sabiam ensinar. Durante séculos o ensino jurídico brasileiro foi baseado nesta crença, e assim, aqueles profissionais que possuíam carreiras brilhantes eram os procurados para dar aulas. Bastava o domínio do conhecimento técnico para transmitir aos alunos.

Isso decorre porque a educação tradicional, ainda com grande força nos dias atuais, e o forte modelo positivista que sempre esteve presente nos cursos de Direito como Bittar (2006) dispõe:

O modelo vigente é herdado desta clássica forma de compreender, de modo liberal e positivista, a realidade do Direito. Uma aula de Direito, no século XIX, sobretudo nas Academias mais tradicionais e mais antigas do Brasil, esta revestida de um simbolismo par. Quase um ritual se segue até que a aula se inicie, ou seja, até quando o lente catedrático comece a proferir sua lectio. A letra da lei parece tão sagrada e inviolável quanto a letra das sagradas escrituras; não pode ser alterada, violada e deve ser capturada em seu sentido mais originário possível. (p.5)

Percebe-se que as aulas eram dotadas de simbolismo, cujo professor, detentor do saber, transmitia seus conhecimentos jurídicos, no caso a letra da lei, inalterada e inviolável para seus ouvintes, os alunos.

Atualmente, mesmo com grandes mudanças ocorridas na educação brasileira, o curso de Direito ainda continua vinculado às práticas dogmáticas e positivistas do século XIX. $O$ ensino jurídico continua mantendo os modelos tradicionais de transmissão de conteúdos de forma tecnicista, e neste sentido Contreras (1998) expõe que:

[...] o ensino entendido como aplicação técnica, como prática dirigida à obtenção de resultados ou produtos previamente definidos, não é uma prática criativa, e sim apenas reprodutiva, dirigida a reproduzir nos alunos os objetivos que guiam o trabalho. (p. 101)

Sendo qualquer tipo de carreira que o egresso de Direito terá, como professor, advogado, promotor, juiz, defensor público, trabalhando em tribunais como analistas ou em qualquer outro meio que necessite o exercício jurídico é inerente à sua atuação as questões ligadas ao interesse social como um todo.

Assim, a educação cidadã, que é um direito fundamental disposto no art. 205, caput da Constituição Federal, afirma que todos devem ter pleno desenvolvimento e preparo para o exercício da cidadania, e este exercício para o operador do Direito merece ainda mais destaque, pois muitos cargos jurídicos são essenciais para o bom desempenho jurisdicional da sociedade.

$\mathrm{Na}$ prática, isso reflete nas decisões que são tomadas diariamente pelos profissionais de Direito, pois ao findar o curso, nota-se que as competências profissionais são limitadas, faltandoIhes a capacidade de resolver situações com rapidez e eficiência. Contreras (1998) ressalta que:

O que o modelo de racionalidade técnica como concepção da atuação profissional revela é sua incapacidade para resolver e tratar tudo o que não pode ser interpretado como um processo de decisão e atuação regulado segundo o sistema de raciocínio infalível, a partir de um conjunto de premissas. (p. 117)

Muito se discute sobre a qualidade do ensino jurídico, que acredita que a grande quantidade de reprovação no Exame da Ordem dos Advogados do Brasil é o termômetro que mede a falta de capacitação desses futuros profissionais. Uma vez que o mercado de trabalho 
exige cada vez mais do profissional competências das quais o processo de formação implica num elevado processo de capacitação, aonde este precisa ser flexível, ter iniciativas e ser capaz de tomar decisões rápidas e eficazes.

Para que tudo isso seja possível é primordial o papel do docente e assim sendo, a sua preparação é indispensável nesse processo como salienta Freitas (2000):

[...] a educação deve ser trabalhada na expressão de formar cidadãos críticos e conscientes que, em decorrência desta percepção, possam em uma primeira etapa se pensarem enquanto seres de cultura e agentes transformadores buscando assim mudarem-se a si próprios e, em seguida, influenciarem as pessoas e o meio em que vivem (p. 2)

Logo, num cenário aonde vemos a importância das mudanças, apresentam-se novas necessidades à prática pedagógica, pois de acordo como ela é apresentada determinará o modo do aprendizado científico, conhecimentos técnicos que serão adquiridos e até mesmo do comportamento social, portanto cabe a cada curso essa tarefa de construir seus projetos pedagógicos para que haja assim uma formação profissional coerente e eficaz.

Portanto a formação docente deve ir além da competência técnica, ou seja, deve também haver uma competência pedagógica, pois é fundamental para que ocorra o perfeito aprendizado. Ao repensar esse novo perfil que o professor de Direito deve ter mudará a maneira como os futuros profissionais agirão diante dos dilemas cotidianos que a profissão lhe apresentar.

O objetivo desde estudo foi nos remeter a oportunidade de refletir e aprofundar o conhecimento sobre o magistério jurídico e como isto influencia no processo de formação do profissional de Direito, bem como contribuir para que o tema em tela amplie espaço cada vez mais efetivo nas preocupações da comunidade acadêmica das ciências jurídicas.

\section{METODOLOGIA}

O referente estudo realizou-se, através do método hipotético-dedutivo; trata-se de um método cientifico que baseia-se em pesquisas de cunho teórico e bibliográfico. Utilizou-se, portanto, a coleta dos dados que nortearam uma possível resolução da problemática apresentada e se deu por meio de livros, artigos eletrônicos, leis, etc. Após a realização de tal coleta, tais dados foram confrontados, destacando-se suas principais ideias com o intuito de chegar o mais próximo da realidade tecendo considerações plausíveis a problemática apresentada.

\section{RESULTADOS}

Os resultados obtidos com a reflexão do artigo em tela nos remetem a uma discussão sobre a importância da formação pedagógica no ensino jurídico para alcançar tal fim, ou seja, a formação humanista do profissional de Direito.

\section{DISCUSSÃO}

Atualmente, uns dos desafios do professor de Direito é ir além da formação tecnicista, ele precisa articular a teoria e prática para que o aluno chegue ao conhecimento. Para isso a docência precisa ser encarada como profissão. Não como um "passatempo" ou um "extra" no salário. 0 professor tem uma missão: a de estimular seus alunos para que estes se tornem independentes, que possam pensar sozinhos, que construam novos saberes para o real exercício jurídico.

Neste sentido Contreras (1998, p. 84) afirma que "o ensino supõe um compromisso de caráter moral para quem o realiza". O professor não pode apenas estar comprometido com suas conquistas acadêmicas, antes de qualquer coisa, seu maior compromisso é com os alunos, de como eles se desenvolverão como pessoas, como cidadãos críticos e reflexivos. 
E isto é um grande desafio para os cursos de Direito, pois é notória a confusão entre o poder e autoridade que exercem em suas atividades fora da academia com as competências educacionais. Sobre este tema Bittar (2006) conclui:

\begin{abstract}
A opressão está em tudo: distância docente, frieza calculista dos olhares, tapetes vermelhos, rituais acadêmicos pomposos e formais, impermeabilidade das congregações ou conselhos acadêmicos, verticalidade das estruturas burocráticas, na feição sisuda do magistrado-professor que adentra a sala de aula sem desvestir-se do cargo, na falta de transparência das políticas das coordenadorias, na massividade impessoal das salas lotadas de pessoas cujas esperanças de ascensão social se depositam sobre o sonho de serem igualmente autoridades, reproduzindo o status quo, em um país onde só se respeita a autoridade do título ou do cargo. (p.29)
\end{abstract}

Sendo assim, num cenário aonde vemos a importância das mudanças, apresentam-se novas necessidades como a formação pedagógica, pois de acordo como ela é apresentada determinará o modo do aprendizado científico, conhecimentos técnicos que serão adquiridos e até mesmo do comportamento social, portanto cabe a cada curso essa tarefa de construir seus projetos pedagógicos para que haja assim uma formação profissional coerente e eficaz.

Esse entendimento pedagógico mostra para o docente de Direito a importância na evolução do seu aluno. E Contreras (1998) relata isso mostrando a relevância do tema:

É inevitável o fato de que o trabalho de ensinar consista na relação direta e continuada com pessoas concretas sobre as quais se pretende exercer influência, com a bondade das pretensões e com os aspectos mais pessoas da evolução, os sentimentos e o cuidado e atenção que podem exigir como pessoas. (p. 85)

Para o autor, quando o professor deixa de ser um transmissor de conhecimento e passa a ser mediador na busca desse conhecimento produz alunos com capacidade de resolver situações das quais ele não espera, mas consegue êxito porque está preparado para enfrentá-las. Contudo, quando o professor os prepara somente para obter a racionalidade técnica e não para ser reflexivo ele os deixa vulnerável para o inesperado:

A rigidez com que se entende a razão da perspectiva positivista é o que provoca essa incapacidade para atender todo o processo de atuação que não se proponha à aplicação de regras definidas para alcançar os resultados já previstos. Por isso, deixa fora de toda consideração aqueles aspectos da prática que têm a ver com o imprevisto, a incerteza, os dilemas e as situações de conflito. Ou seja, com todas aquelas situações das quais as regras técnicas e os cálculos não são capazes de dar conta e para as quais se requerem outras capacidades humanas que têm de ser entendidas e não desprezadas. É exatamente ali aonde as regras técnicas não chegam que mais falta fazem aquelas habilidade humanas relacionadas com a capacidade de deliberação, reflexão e de consciência. (CONTRERAS, 1998, p. 117)

Isso ocorre porque durante a sua formação foi apresentado apenas processos para a resolução de problemas de acordo com determinados fins, e não buscou-se refletir sobre quais seriam os fins e qual o significado concreto dessas situações complexas exigiriam dele.

Assim, num mercado que exige cada vez mais dos profissionais competências das quais o processo de formação implica num elevado processo de capacitação, no qual este precisa ser flexível, ter iniciativas e ser capaz de tomar decisões rápidas e eficazes. Schön (apud Contreras, 1998) propõe que o profissional deve ser reflexivo, ou seja:

[..] enfrentam aquelas situações que não se resolvem por meio de repertório técnicos; aquelas atividades que, como o ensino, se caracterizam por atuar sobre situações que são incertas, instáveis, singulares e nas quais há conflitos de valor. (p. 118) 
Logo, para que o aluno possa desenvolver essas várias competências o entendimento pedagógico é essencial na formação do docente de ensino superior, para que este possa entender a verdadeira relação que existe entre professor- aluno e desenvolver com eficácia o ensinoaprendizagem e isto irá refletir na futura jornada profissional que esses alunos terão, pois se tornarão profissionais reflexivos e não somente possuidores de uma racionalidade técnica.

\section{CONCLUSÃO}

Com os breves apontamentos presente neste trabalho observou-se que saber fazer não equivale a saber ensinar. A falta de preparo pedagógico por parte dos docentes acarreta grandes prejuízos nas competências e habilidade que o egresso de Direito tem ao findar seu curso. Pois conforme dispõe Giorgi e Leite (2004):

[...] confundir ensino apenas como uma técnica de transmissão do saber, do conhecimento convertido em informação, da verdade acabada e dos conteúdos a serem consumidos pelos alunos, é esquecer que o ensino é e deve se realizar como dimensão essencial do processo de criação de sujeitos da cultura, de pessoas que interrogam, de pessoas que pensam e recriam a realidade, o mundo e a existência humana.

Assim, diante de novos paradigmas e exigências, o docente universitário necessita obter, além de sua formação técnica, uma formação pedagógica, pois não basta apenas ensinar a lei, o processo ou as tendências jurisprudenciais, é preciso sair da lógica da racionalidade positivista para formar alunos que possam construir uma sociedade livre, justa e solidária através do exercício do Direito.

E para que se possa desenvolver esses valores, o professor deve ter em mente que a qualidade de seu ensino e o seu comprometimento com o aluno determinará o desempenho profissional que o operador do Direito terá e a sociedade também se beneficiará, pois terá profissionais mais humanista, críticos e reflexivos.

\section{REFERÊNCIAS}

BITTAR, E.C.B. Estudos sobre o ensino jurídico: pesquisa, metodologia, diálogo e cidadania. São Paulo: Atlas. 2006

CONTRERAS, J. Autonomia do professor. Os valores do profissionalismo e a Profissionalidade docente. São Paulo: Editora Cortez, p. 79-89, 1998.

CONTRERAS, J. Autonomia do professor. A autonomia ilusória: O professor como profissional técnico. São Paulo: Editora Cortez, p. 90-104, 1998.

CONTRERAS, J. Autonomia do professor. O docente como profissional reflexivo.. São Paulo: Editora Cortez, p. 117-146, 1998

COELHO, A. M. S; PEREIRA, J. E. D. Olhar o magistério "no próprio espelho": O conceito de Profissionalidade e as possibilidades de se repensar o sentido da profissão docente. Revista Portuguesa de Educação, v. 30, n.1, p.7-34, 2017. https://doi.org/10.21814/rpe.10724

FREITAS, N. O. Ensaio sobre a educação brasileira e o ensino jurídico: o ensino jurídico na graduação. Revista OAB Goiás, ano XIV, n. 42, abr./jun. 2000. Disponível em: http://www.oabgo.org.br/Revistas/42/juridico_42.htm . Acesso em: jun. 2016. 
LEITE, Y. U. F.; Di GIORGI. C. A. G.. Saberes docentes de um novo tipo na formação profissional do professor: alguns apontamentos. Educação, v.29, n. 2, p. 135-145, Santa Maria- RS, 2004. 